\title{
Review: Effects of Dietary Fiber Levels and Composition on the Intestinal Health of Finishing Pigs
}

\author{
Gwen Mozamane Tiishetso Maswanganye, Bo Liu, Dongsheng Che, Rui Han \\ Animal Science and Technology, Jilin Agricultural University, Changchun, China \\ Email: tiishetsomaswanganye@gmail.com
}

How to cite this paper: Maswanganye, G.M.T., Liu, B., Che, D. and Han, R. (2021) Review: Effects of Dietary Fiber Levels and Composition on the Intestinal Health of Finishing Pigs. Open Journal of Animal Sciences, 11, 384-398.

https://doi.org/10.4236/ojas.2021.113028

Received: April 7, 2021

Accepted: June 14, 2021

Published: June 17, 2021

Copyright (c) 2021 by author(s) and Scientific Research Publishing Inc. This work is licensed under the Creative Commons Attribution-NonCommercial International License (CC BY-NC 4.0). http://creativecommons.org/licenses/by-nc/4.0/

\begin{abstract}
Despite the fact that dietary fiber is predominant in common feedstuff, its level in the diets of monogastrics has seen a proportional increment with the inclusion of co-products. The source and composition of DF could be liable for enormous varieties in their use. A study carried out by scientists proposed that three major components constitute gut health: the diet, the mucosa, and the commensal microbiota. $70 \%$ of total body immune cells constitute the gastrointestinal tract of pigs, therefore it is important that it is included when defining intestinal health. Gut health is of substantial importance in the maintenance of growth performance and overall health of monogastrics. The fermentation of DF results in SCFA which enhances mucosal epithelial proliferation and villus height. Nonetheless, supplementing dietary fiber to the diet in moderation may result in an increase in gut size, volume, length and morphological structure of pigs and other non-ruminants. Gut health maintenance exhibits a certain level of complexity and a subtle balance between mucosa, diet, the commensal microflora, including the digestive epithelium and along with mucous overlaying it. The microbial changes of dietary fiber to monosaccharides in the gut include various principal occasions (reactions) intervened by the enzymatic collection of particularized groups from the gut microbiota. Because fermentation is dependent upon source, structure and physio-chemical properties of dietary fiber, it is therefore of great importance to have as much data as possible on various types of dietary fiber and how intestinal health can be enhanced by them. Thus, there is growing evidence that dietary fiber may have prebiotic effects in pigs. In addition, dietary fiber in diets improves pigs well-being by increasing satiety, influencing behaviour and improving overall health. This review aims to shed more light on the dietary fiber levels and composition on the intestinal health of finishing pigs.
\end{abstract}




\section{Keywords}

Intestinal Health, Dietary Fiber, Fermentation, Gut Microbiota, Immunity

\section{Introduction}

Despite the fact that dietary fiber (DF) is predominant in common feedstuff, its level in the diets of monogastrics has seen a proportional increment with the inclusion of co-products. Various studies have shown that dietary fiber can provide animals with nutritional value, directly by acting as a source of energy [1] and indirectly by enhancing immune function and gut health [2] [3]. Throughout history, dietary fiber has been thought of as an antinutritional factor as a result of its negative effects on the utilization of nutrients [4] [5]. However, the paradigm has since shifted and dietary fiber received extraordinary attention due to its functional value on the enhancement of monogastric gut health [6]. The enhancement and maintenance is crucial to improve promote growth performance, feed efficiency and maintain the overall health of monogastric animals. For over 6 decades, Antibiotic growth promoters (AGP) have been incorporated in feeding regimes as a means to promote gut health and in turn, enhance growth performance of production animals. As a result of potential health hazards coupled with the use of AGP, these substances have been prohibited or under strict regulation in some countries. As an attempt to subdue the undesirable impacts of AGP, various alternatives have been proposed and tested; with dietary being at the forefront as one of the effective alternatives of AGP [6].

Dietary fibers are diverse compounds occurring in nature and all plant-based feed-stuffs contain them [7] [8]. There has been an increasing interest in supplementing dietary in diets fed to monogastric animals as a result of potential beneficial effects on the welfare, environment and most importantly for this study: gut health [9]. The endogenous enzymes in the proximal small intestines cannot digest dietary fiber but the microbes residing in the distal small intestine and large intestine utilize them as fermentative substrates. Through this microbial fermentation, metabolites such as small-chain fatty acids (SCFA) are produced, which ultimately enhances the growth of beneficial gut bacteria, offering support to intestinal integrity and proper immune function.

Studies with pigs and poultry have shown that fermentation characteristics and their beneficial effects on gut health vary widely based on type, form, and the physico-chemical properties of the DF [9] as well as the matrix in which it lies [10]. Therefore, it is important to have information on the different types of DF and their specific roles in optimizing gut health of monogastric animals.

\section{Literature Review}

\subsection{Dietary Fiber}

The definition of dietary fiber can be explained in various ways [1]; the most 
common one is on the basis of chemical composition and physiological functions. From a chemical composition point of view, dietary fiber is the total of non-starch polysaccharides (NSP) and lignin. Nutritionists simply define it as carbohydrates that are resistant to digestion by endogenous enzymes. There are several common feed components that are fiber-rich such as wheat, oats, barley and other co-products like wheat millrun and canola meal. Broadly speaking, dietary fiber is comprised of cell wall constituents of hemicellulose, cellulose and other structural and non-structural compounds resistant starch (RS), chitin, insulin, pectin oligosaccharides and $\beta$-glucan. Resident microbes in the distal small intestines and large intestines are responsible for the rapid fermentation of the sources of soluble fiber and this subsequently decreases digesta passage rate, elevates digesta viscosity and can reduce feed intake as a result of elevated satiety.

Undigested insoluble fiber makes its way through the intestines, resulting in increased fecal bulking and passage rate; nevertheless, there's a limitation to monogastrics' capacity to carry out the fermentation of insoluble fiber due to the lack of specific species of microbes [11] [12]. Hence, it is crucial to have an extensive understanding of DF components along with its nutritional and physiological effects in animals before its incorporation into the diets of monogastrics is considered. For studies detailing the composition of dietary fiber, its sources and how it is utilized in various portions of the gastro-intestinal tract (GIT), it is recommended that readers refer to a paper published by [9], which provides updated extensive information on these topics.

\subsection{Dietary Fiber Sources and Their Use in Pig Diets}

The source and composition of DF could be liable for enormous varieties in their use [13]. The physico-compound properties of the DF sources may prompt changes in the gut climate, causing a change in the development of the gut microflora. The acceptability of the alternate ingredients of feed in the diet of pigs relies upon a few elements, similar to the DF content, the level of microbial fermentation in the large intestines and the degree of assimilation and use of the volatile fatty acid (VFA) produced [14]. The fermentation of fiber sources occurs in the GIT and this process produces VFAs, which has a subsequent positive influence on gut wellbeing [15]. [16] made a note that pig diets that contain adequate and suitable sources of primarily soluble NSP instead of insoluble NSP grant gut health the most benefit. Soluble DF is comprised of hemicelluloses, pectins, $\beta \mathrm{G}$, and gum, whereas the insoluble fraction is composed of cellulose and lignin [17]. Consequently, it is basic to know the source and kind of fiber being provided in the diets of pigs.

There is expanding interest and motivation for the recognition and characterization of substitute feed ingredients. These alternatives encompass legume grains and cereals, distillery coproducts, coproducts from the oil industry (like canola meal) and wheat flour milling (millrun and bran), and other fibrous feeds. 
Cereal grains along with their coproducts are responsible for the crucial part of pig rations as principal energy sources. The DF contained in cereal grains are chiefly comprised of NSP ( $\beta$ G, AX, cellulose and arabinoxylans) and noncarbohydrate component lignin [18]. Furthermore, limited quantities of pectin substances are found in the stems and leaves of cereals [19]. A few laborers referenced that the level of DF in the ordinarily accessible feed ingredients change with regards to type and quality. Sorghum, rye, wheat and corn are for the most part wealthy in $\mathrm{AX}$, though oats and barley contain a significant level of $\beta \mathrm{G}$. The $\mathrm{AX}$ from rye and wheat and $\beta \mathrm{G}$ from oats and barley are to an enormous degree soluble, while AX contained in sorghum and corn exhibit low solubility as opposed to other cereals [20].

\subsection{Intestinal Health}

The largest group of organs in the body is known as the GIT. The GIT serves different types of functions other than being a site for nutrient digestion and absorption, it also provides protection against pathogens and toxins. Furthermore, an ample population of microbiota and immune cells are found in it. Therefore, a healthy intestinal tract is crucial for overall sound health and enhanced animal productivity. Nonetheless, the definition of "intestinal health" or "gut health" is not yet clearly discussed, despite it being the centre of attention for the past few decades. A study carried out by [21] proposed three major components constitute gut health: the diet, the mucosa, and the commensal microbiota. Subsequently, [22]'s work detailed that it includes a diet that would render adequate nutrients, a microbial community that maintains a stable, healthy environment and mucosa for the maintenance of the gut integrity. 70\% of total body immune cells constitute the gastrointestinal tract of pigs, therefore it is important that it is included when defining "intestinal health". Therefore, it is recommended that the intestinal health be looked at as a complex that includes microbiota, diet and the immune system (Figure 1). The constituents of pigs' GIT are the microbiome (archaea, fungi, protists viruses and bacteria), non-hemopoietic cells (goblet cells, epithelia and paneth cells) and hemopoietic cells (T-cells, macrophages and dendritic cells) all of which gut health depends

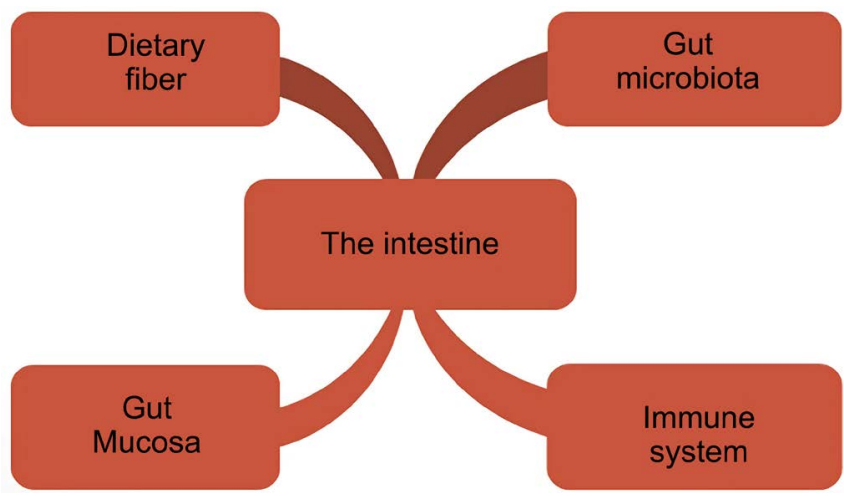

Figure 1. Components of gut health in a holistic approach. 
upon. The innate and adaptive immune systems are in constant communication with the microbiota for homeostasis maintenance. It is very crucial that the immune system remains in balance because any disruption in this balance can cause dysbiosis and subsequently elevated susceptibility to various diseases [23]. The intestinal mucosa comprises the epithelium, the gut-associated lymphoid tissue (GALT), and the mucus overlying the epithelium. A delicate and dynamic equilibrium, which is crucial to a streamlined functioning and absorption capacity of the digestive system, is formed as a result of the interaction between the GALT, the intestinal mucus, host epithelial cells and microbiome. The translocation of microbial population, which would cause systemic immune activation, is prevented by the chemical (antibacterial proteins, acidity, proteolytic enzymes and lysozymes) and physical (mucus, epithelial cells and intercellular tight junction) barriers. Additionally, the aforementioned barriers play an essential role in the gut barrier function maintenance. The function of the epithelial cells goes beyond just serving as a physical barrier, they also secrete chemokines and cytokines that are responsible for the regulation of chemotaxis of immune cells. Paneth cells are located at the base of the crypts of many vertebrate species, including poultry. Bacterial-induced (not during infection caused by protozoa or fungi) inflammation is counteracted by defensin rich granules that are released as a consequence of the inflammation [24]. The maintenance and restoration $f$ the intestinal mucosal integrity is made possible by three mucosal barrier factors: transforming, trefoil factor and diamine oxidase Three tight junction proteins namely zona occludens-1, claudin and occludin, are responsible for the maintenance of the para-cellular barrier [25]. As previously established, various factors go into maintaining the gut barrier. Goblet cells located in the GIT also play a crucial in this maintenance. They do so by producing mucin which serve functions from lubrication to cell signaling to forming chemical barriers. Bacteria are important in the production of mucin. Several bacteria such as Lactobacillus enhance mucin production [26], which aid in the improvement of the gut barrier as pathogens are obstructed by the dense layer of mucous. Nonetheless, an absolute absence of pathogenic microbiota does not characterize an ideal gut health, instead an intestinal microbiome with substantial microbial and functional diversity.

\subsection{The Relationship between Dietary Fiber and Intestinal Mucosa/Histomorphology}

Gut health is of substantial importance in the maintenance of growth performance and overall health of monogastrics and it is impacted by the interaction of several factors in the intestines (Figure 2). The fundamental function of intestinal mucosal tissue is absorption and digestion of nutrients. The host hydrolzes and breaks down the ingredients of feed into tinier compounds; amino acids, peptides from proteins, fatty acids, monoglycerol from lipids and starch all contain glucose which is obtained by the mucosa. The fermentation of DF results in SCFA which enhances mucosal epithelial proliferation and villus height [27]. The exchange of nutrients to the body is modulated by mucosal epithelial layer 
[28]. In addition to intestinal secretions and brush border membrane producing glycoproteins, mucosal epithelium has a significant influence on the adhesiveness capacity the metabolic activity of microbes in the intestines. Therefore, toxic compounds and pathogenic bacteria are barred by the intestinal mucosa. The intestinal mucosal barrier is constructed by both the adaptive and innate immune systems. Including DF in diets frequently results in an increase in endogenous losses. Subsequently, a decrease in energy and nutrients digestion can be observed in monogastric animals. As a result, DF has since been perceived as "anti-nutritive" for monogastric animals. Furthermore, these negative effects are more common in piglets than in growing and finishing pigs [29]. Nonetheless, supplementing dietary fiber to the diet in moderation may result in an increase in gut size, volume, length and morphological structure of pigs and other non-ruminants. There is an increase in the viscosity of the intestinal content when piglets diets are supplemented with soluble fiber and a subsequent increase in the rate of villus cell losses leading to villus atrophy [30]. The ratio of villus height to crypt depth is a helpful point of reference for the estimation of the presumptive small intestine digestive capacity. Including $10 \%$ high fiber source in the diets of growing pigs for a period of 14 days has resulted in an increase in villi width and crypts depth in the ileum and jejunum. Furthermore, elevated rates of cell proliferation and crypt depth were observed in the large intestines, as opposed to the same diet devoid of straw [31]. Nonetheless, crypt depth and villus height remain unchanged in the gut; its mutability is dependent upon the location of the small intestines. Consequently, an evaluative apprehension of the mechanisms of nutrient absorption, and where specific nutrient utilization is located for the development of enhanced feeding regime to attain exceptional production performance is highly required.

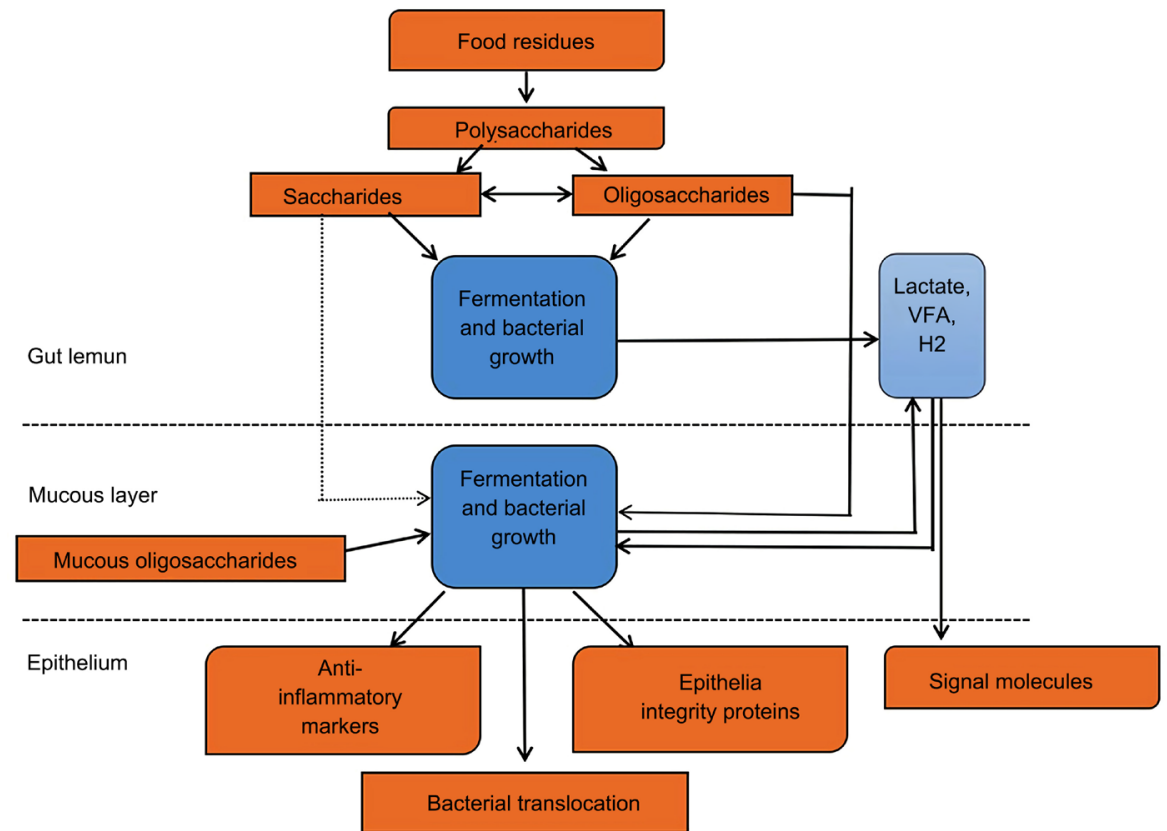

Figure 2. Interactions between dietary fiber, gut environment, gut microbiota and host response with implications on gut health. 


\subsection{Effects of Dietary Fiber on Gut Health}

\subsubsection{Microenvironment of the Gut}

Gut health maintenance exhibits a certain level of complexity and a subtle balance between mucosa, diet, the commensal microflora, including the digestive epithelium and along with mucous overlaying it [32]. Gut health is greatly influenced by the diet and the input could either be desirable or harmful [33]. The diet should be formulated in a manner that promotes a balance between the gut, the gut environment and the microbiota and prevent disturbances in the gut. There's an interaction between the dietary fiber and both the microbiota and mucosa, and this interaction has a consequence importance in controlling the health of the gut [34]. The diverse microbial population in GI comprises numerous classes of microbes, including archaea, bacteria, ciliate, protozoa and flagellate, fungus, bacteriophages. Bacteria are the most common and studied bacteria in the world. They are supplied with dietary substrates as well as host-derived components such as mucopolysaccharides, mucins, epithelial cells and enzymes [35]. With the advent of molecular techniques to classify the microbiota, it has become clear that only a minority of GI microbes have been isolated by culture-based methods [36] and, as a result, information that we're in possession of needs revision in future.

\subsubsection{Prebiotic Effects}

Initially the prebiotics definition was described as the "non-digestible food ingredient that affects the host selectively by encouraging one or more bacteria to develop and/or function in the colone, thereby enhancing host health" [37]. However, the drawback of this concept is that almost any food, oligosaccharides and polysaccharides can be claimed to have prebiotic activity (including dietary fiber). It was subsequently suggested that a compound should be labeled as a prebiotic and that the scientific proof be drawn that it is immune to processes of host digestion, absorption and adsorption processes, is fermented by a GI system microbiota, and selectively triggers one or a small number of bacteria to grow and/or function inside the GI system [38]. Dietary fiber (DF) is an element that has a significant impact in this context. Dietary fiber products are not digested by the digestive enzymes and are thus the key substrates in the distal part of the gut for bacterial fermentation. The fermentation products are primarily lactates, acetates, propionates and butyrates $(\mathrm{OA})$ in short chain fatty acids. The OA was proposed to improve digestive tract growth by stimulating the proliferation of the epithelial cells [39]. OA can inhibit enteric bacterial pathogens like Salmonella, groups of $E$. coli and clostridium from growing in an acidic environment [40]. The different types of plant carbohydrates have been shown to have different behaviours in the GIT depending on their structural characteristics in studies carried out in pigs. The inclusion of soluble NSP will improve Commensal gut microorganic growth in the diet, leading to higher productivity of $\mathrm{OA}$ and a lowness of $\mathrm{pH}$ in the broad gut [41]. Insoluble NSP decreases the transit period and offers a steadily microbiota-degradable substrate in the distal large intestine 
[42] and modulate villus morphology by increasing its length [43]. The proliferation of enterotoxic $E$. coli is enhanced by the inclusion of guar gum, a soluble and viscous NSP, in a diet [44], while feeding insoluble NSP lessens the event of haemolytic E. coli, and diminishes the severity of post weaning colibacillosis [45]. Nonetheless, it was indicated that soluble NSP essentially is not adverse to piglet well-being [46]. Rather it was expressed that soluble NSP that does not increase the viscosity of digesta may advantageously influence gut well-being by expanding the lactobacilli:coliform proportion and reduce the event of weaning diarrhoea. The effect of DF source on gut microbiota composition and gut micro-environment was clearly shown in a recent report on chicory. Including chicory (Cichorium intybus L.) scrounge and root in a grain-based diet (wheat and barley) brings about changes in gut morphology and micro-environment of pigs [47], whereas growth development was not affected and digestibility was just insignificantly diminished by chicory inclusion [48] [49]. Within the type of diet, these progressions followed a comparable pattern in both the small and large intestines. Nonetheless, the dietary reactions were distinctive with incorporation of chicory root contrasted with chicory scrounge. This could be identified with the chemical composition of the dietary fiber portion [50], where the root is characterized by high content of inulin-type fructan and oligofructose, while the scrounge is described by high content of pectin.

\subsection{Microbial Fermentation Products: Small Chain Fatty Acids}

Dietary fibers, but peptides and proteins are included, which bypass host enzyme digestion in the upper gut, undergo metabolism carried out by the microbiota located in the colon and caecum [51]. Microbial fermentation produces major products known as the SCFAs-particularly butyrate, acetate and propionate [52]. Nonetheless, there are cases where fermentable fibers are in a limited supply and in such cases energetically less desirable sources for growth such as dietary fats or amino acids from dietary endogenous or dietary proteins [53] [54] become the microbes last resort, and this results in a decline in microbiota fermentation activity and SCFAs as minor end products [55]. The SCFA pool receives a contribution from proteins when they are fermented but protein fermentation predominantly produces branched-chain fatty acids such as 2-methylbutyrate, isovalerate and isobutyrate, solely developing from branched-chain amino acids isoleucine, leucine and valine [56], which are implicated in insulin resistance [57]. A further supplementation of a protein- or fat-rich diet with adequate dietary fiber rejuvenates advantageous microbes, reduces poisonous metabolites produced by microbes and elevates SCFAs [58].

\subsection{Biosynthesis of Small Chain Fatty Acids, Absorption and Distribution}

The microbial changes of dietary fiber to monosaccharides in the gut include various principal occasions (reactions) intervened by the enzymatic collection of particularized groups from the gut microbiota. Significant finished results from 
these fermentation processes are the SCFAs. One of the major SCFAs, acetic acid derivation (acetate), can be created from pyruvate by numerous gut bacteria either through acetyl-CoA or by means of the Wood-Ljungdahl pathway in which acetate is produced through two branches: 1 ) the $\mathrm{C}_{1}$-body branch (otherwise called Eastern branch) through reducing $\mathrm{CO}_{2}$ to formate and 2) the carbon monoxide branch (the Western branch) through reducing $\mathrm{CO}_{2}$ to $\mathrm{CO}$, which is additionally joined with a methyl group to create acetyl-CoA [59]. Another major SCFA, propionate, is synthesized when succinate is converted to methylmalonyl-CoA by means of the succinate pathway. Propionate can likewise be produced from acrylate where lactate serves as a precursor through the acrylate pathway [60] and through the propanediol pathway, in which deoxyhexose sugars, (for example, fucose and rhamnose) are substrates [61]. Butyrate is the third major SCFA, which is synthesized when two molecules of acetyl-CoA condense together and subsequently reduced to butyryl-CoA, which can be changed over to butyrate through the supposed traditional pathway, by phosphotransbutyrylase and butyrate kinase [62]. Butyryl-CoA can likewise be changed to butyrate by the butyryl-CoA:acetate CoA-transferase course [63].

Acetate and lactate can be utilized by certain microbes in the gut for the synthesis of butyrate which is preclude lactate from accumulating and ensures that the instestinal environment is stable. Metagenome data analyzed brought forth a suggestion that the synthesis of butyrate from proteins is also possible through the lysine pathway, further implying gut microbes are capable of adapting to nutritional switches in order to ensure maintenance in the production of essential metabolites such as SCFAs. There are variations in the concentrations of SCFAs along the length of the gut, with caecum and proximal colon housing the highest levels and the distal colon housing the lowest levels [64]. The low concentration of SFCAs can be explained by elevated absorption through the $\mathrm{Na}^{+}$-coupled monocarboxylate transporter SLC5A8 and $\mathrm{H}^{+}$-coupled low affinity monocarboxylate transporter SLC16A1. The most preferred source of energy for colonocytes is butyrate and is consumed locally, while other absorbed SCFAs drain into the portal vein. Metabolism of proprionate takes place in the liver and therefore is only present in the periphery at low concentrations, deeming acetate the most abundant SCFA in peripheral circulation [65]. Moreover, the blood-brain barrier can be crossed by acetate and appetite can subsequently be reduced via a central homeostatic mechanism [66]. Regardless of the low concentrations in the periphery, propionate and butyrate have an indirect effect on the peripheral organs by activating nervous and hormonal systems.

\subsection{Immune Modulation by Metabolites}

In spite of the fact that microbial and host fermentation occurs alongside each other, the host is dependent upon its microbiota for an expanded assemblage of metabolix and digestive enzymes [67]. A vast array of metabolite repertoire is produced by the gut microbiota through anaerobic fermentation of external dietary components that have not undergone digestion and make their way to the 
colon. Furthermore, metabolites are also produced from endogenous compounds from the host and microorganism. Microbial metabolic products are allowed entry into and interaction with host cell by the single layer of epithelial cells that constitute the mucosal interface between microorganisms and the host. This interaction has an influence on disease risk and immune responses. As previously mentioned, complex carbohydrates that have not undergone digestion by the host are a tremendous source of substrates for bacterial fermentation in the colon, and their principal end products are SCFAs. The concentration of SCFAs in the gut (which may range anywhere between $20-140 \mathrm{nM}$ ) [68] is dependent upon the composition of microbiota.

\section{Conclusion}

Dietary fiber effects on pig nutrition and health are determined by its properties, which can vary greatly between sources of fiber. Furthermore, different methods can be used to increase the use of dietary fiber. Due to interactions between the gut-associated immune system and gut micro-environment, there is growing evidence that dietary fiber may have prebiotic effects in pigs. This property can be manipulated and used to promote gut health and as a result, reduce the use of antimicrobial growth promoters. In addition, dietary fiber in diets improves pigs well-being by increasing satiety, influencing behaviour and improving overall health.

\section{Funding}

This work was financially supported by the Scientific and Technology Development Project of Jilin Province (20190301039NY).

\section{Conflicts of Interest}

The authors declare no conflicts of interest regarding the publication of this paper.

\section{References}

[1] Varel, V.H. and Yen, J.T. (1997) Microbial Perspective on Fiber Utilization by Swine. Journal of Animal Science 75, 2715-2722. https://doi.org/10.2527/1997.75102715x

[2] Choct, M., Hughes, R.J., Wang, J., Bedford, M.R., Morgan, A.J. and Annison, G. (1996) Increased Small Intestinal Fermentation Is Partly Responsible for the Anti-Nutritive Activity of Non-Starch Polysaccharides in Chickens. British Poultry Science, 37, 609-621. https://doi.org/10.1080/00071669608417891

[3] Pieper, R., Jha, R., Rossnagel, B., Van Kessel, A., Souffffrant, W.B. and Leterme, P. (2008) Effect of Barley and Oat Cultivars with Different Carbohydrate Compositions on the Intestinal Bacterial Communities in Weaned Piglets. FEMS Microbiology Ecology, 66, 556-566. https://doi.org/10.1111/j.1574-6941.2008.00605.x

[4] Jha, R., Rossnagel, B., Pieper, R., Van Kessel, A. and Leterme, P. (2010) Barley andoat Cultivars with Diverse Carbohydrate Composition Alter Ileal and Total Tract Nutrient Digestibility and Fermentation Metabolites in Weaned Piglets. Animal, 4, 
724-731. https://doi.org/10.1017/S1751731109991510

[5] Annison, G. (1993) The Role of Wheat Non-Starch Polysaccharides in Broiler Nutrition. Australian Journal of Agricultural Research, 44, 405-422.

https://doi.org/10.1071/AR9930405

[6] Jha, R. and Berrocoso, J.D. (2015) Dietary Fiber Utilization and its Effects on Physiological Functions and Gut Health of Swine. Animal, 9, 1441-1452. https://doi.org/10.1017/S1751731115000919

[7] Chabeauti, E., Noblet, J. and Carre, B. (1991) Digestion of Plant Cell Walls from Four Different Sources in Growing Pigs. Animal Feed Science and Technology, 32, 207-213. https://doi.org/10.1016/0377-8401(91)90024-M

[8] Molist, F., van Oostruma, M., Pérez, J.F., Mateos, G.G., Nyachoti, C.M. and van der Aar, P.J. (2014) Relevance of Functional Properties of Dietary Fibre in Diets for Weanling Pigs. Animal Feed Science and Technology, 189, 1-10.

https://doi.org/10.1016/j.anifeedsci.2013.12.013

[9] Lindberg, J.E. (2014) Fiber Effects in Nutrition and Gut Health in Pigs. Journal of Animal Science and Biotechnology, 5, Article No. 15.

https://doi.org/10.1186/2049-1891-5-15

[10] Wellock, I.J., Houdijk, J.G.M. and Kyriazakis, I. (2007) Effect of Dietary Non-Starch Polysaccharide Solubility and Inclusion Level on Gut Health and the Risk of Post Weaning Enteric Disorders in Newly Weaned Piglets. Livestock Science, 108, 186-189. https://doi.org/10.1016/j.livsci.2007.01.050

[11] Davidson, M.H. and McDonald, A. (1998) Fiber: Forms and Functions. Nutrition Research, 18, 617-624. https://doi.org/10.1016/S0271-5317(98)00048-7

[12] Bach Knudsen, K.E. (2014) Fiber and Nonstarch Polysaccharide Content and Variation in Common Crops Used in Broiler Diets. Poultry Science, 93, 2380-2393. https://doi.org/10.3382/ps.2014-03902

[13] Choct, M. (1997) Feed Non-Starch Polysaccharides: Chemical Structures and Nutritional Significance. Feed Milling International, 6, 13-26.

[14] Serena, A. and Knudsen, K.E.B. (2007) Chemical and Physicochemical Characterisation of Co-Products from the Vegetable Food and Agro Industries. Animal Feed Science and Technology, 139, 109-124.

https://doi.org/10.1016/j.anifeedsci.2006.12.003

[15] Tiwari, U.P. and Jha, R. (2016) Nutrient Profile and Digestibility of Tubers and Agro-Industrial Coproducts Determined Using an in Vitro Model of Swine. Animal Nutrition, 2, 357-360. https://doi.org/10.1016/j.aninu.2016.07.004

[16] Tiwari, U.P. and Jha, R. (2017) Nutrients, Amino Acid, Fatty Acid and Non-Starch Polysaccharide Profile and in Vitro Digestibility of Macadamia Nut Cake in Swine. Animal Science Journal, 88, 1093-1099. https://doi.org/10.1111/asj.12750

[17] Jha, R. and Berrocoso, J.F.D. (2016) Dietary Fiber and Protein Fermentation in the Intestine of Swine and Their Interactive Effects on Gut Health and on the Environment: A Review. Animal Feed Science and Technology, 212, 18-26.

https://doi.org/10.1016/j.anifeedsci.2015.12.002

[18] Jha, R., Woyengo, T.A., Li, J., Bedford, M.R., Vasanthan, T. and Zijlstra, R.T. (2015) Enzymes Enhance Degradation of the Fiber-Starch-Protein Matrix of Distillers Dried Grains with Solubles as Revealed by a Porcine in Vitro Fermentation Model and Microscopy. Journal of Animal Science, 93, 1039-1051. https://doi.org/10.2527/jas.2014-7910

[19] Mateos, G.G., Guzman, P., Saldana, B., Bonilla, A.P., Lazar, R. and Jimenez-Moreno, 
E. (2013) Relevance of Dietary Fiber in Poultry Feeding. European Symposium of Poultry Nutrition, Potsdam.

[20] Conway, P. (1994) Function and Regulation of the Gastrointestinal Microbiota of the Pig. In: Souffrant, W. and Hagemeister, H., Eds., Proceedings of the 6 th International Symposium on Digestive Physiology in Pigs, 231-240.

[21] Montagne, L., Pluske, J. and Hampson, D. (2003) A Review of Interactions between Dietary Fibre and the Intestinal Mucosa, and Their Consequences on Digestive Health in Young Non-Ruminant Animals. Animal Feed Science and Technology, 108, 95-117. https://doi.org/10.1016/S0377-8401(03)00163-9

[22] Chassaing, B., Kumar, M., Baker, M.T., Singh, V. and Vijay-Kumar, M. (2014) Mammalian Gut Immunity. Biomedical Journal, 37, 246-258.

https://doi.org/10.4103/2319-4170.130922

[23] Platt, A.M. (2017) Immunity in the Gut: Mechanism and Functions. Viral Gastroenteritis, 351, 1329-1333.

[24] Runkle, E.A. and Mu, D. (2013) Tight Junction Proteins: From Barrier to Tumorigenesis. Cancer Letters, 337, 41-48. https://doi.org/10.1016/j.canlet.2013.05.038

[25] Chen, H., Mao, X., He, J., Yu, B., Huang, Z., Yu, J., et al. (2013) Dietary Fibre Affects Intestinal Mucosal Barrier Function and Regulates Intestinal Bacteria in Weaning Piglets. British Journal of Nutrition, 110, 1837-1848.

https://doi.org/10.1017/S0007114513001293

[26] Bach Knudsen, K.E., Hedemann, M.S. and Lærke, H.N. (2012) The Role of Carbohydrates in Intestinal Health of Pigs. Animal Feed Science and Technology, 173, 41-53. https://doi.org/10.1016/j.anifeedsci.2011.12.020

[27] Johnston, L.J., Noll, S., Renteria, A. and Shurson, J. (2003) Feeding By-Products High in Concentration of Fiber to Nonruminants. The 3 rd National Symposium on Alternative Feeds for Livestock and Poultry, Kansas City, 4 November 2003, 169-186.

[28] Hedemann, M.S., Eskildsen, M., Lærke, H.N., Pedersen, C., Lindberg, J.E., Laurinen, P., et al. (2006) Intestinal Morphology and Enzymatic Activity in Newly Weaned Pigs Fed Contrasting Fiber Concentrations and Fiber Properties. Journal of Animal Science, 84, 1375-1386. https://doi.org/10.2527/2006.8461375x

[29] Jin, L., Reynolds, L.P., Redme, D.A., Caton, J.S. and Crenshaw, J.D. (1994) Effects of Dietary Fiber on Intestinal Growth, Cell Proliferation, and Morphology in Growing Pigs. Journal of Animal Science, 72, 2270-2278. https://doi.org/10.2527/1994.7292270x

[30] Le Gall, M., Warpechowski, M., Jaguelin-Peyraud, Y. and Noblet, J. (2009) Influence of Dietary Fibre Level and Pelleting on the Digestibility of Energy and $\mathrm{Nu}$ trients in Growing Pigs and Adult Sows. Animal, 3, 352-359.

https://doi.org/10.1017/S1751731108003728

[31] Bach Knudsen, K.E. (2001) The Nutritional Significance of "Dietary Fibre" Analysis. Animal Feed Science and Technology, 90, 3-20. https://doi.org/10.1016/S0377-8401(01)00193-6

[32] de Leeuw, J.A., Bolhuis, J.E., Bosch, G. and Gerrits, W.J.J. (2008) Effects of Dietary Fibre on Behaviour and Satiety in Pigs. Proceedings of the Nutrition Society, 67, 334-342. https://doi.org/10.1017/S002966510800863X

[33] Bikker, P., Dirkzwager, A., Fledderus, J., Trevisi, P., Le Huerou-Luron, I., Lalles, J.P. and Awati, A. (2006) The Effect of Dietary Protein and Fermentable Carbohydrates Levels on Growth Performance and Intestinal Characteristics in Newly Weaned Piglets. Journal of Animal Science, 84, 3337-3345.

https://doi.org/10.2527/jas.2006-076 
[34] Le Goff, G., van Milgen, J. and Noblet, J. (2002) Influence of Dietary Fibre on Digestive Utilization and Rate of Passage in Growing Pigs, Finishing Pigs and Adult Sows. Animal Science, 74, 503-515. https://doi.org/10.1017/S1357729800052668

[35] Zoetendal, E.G., Collier, C.T., Koike, S., Mackie, R.I. and Gaskins, H.R. (2004) Molecular Ecological Analysis of the Gastrointestinal Microbiota: A Review. The Journal of Nutrition, 134, 465-472. https://doi.org/10.1093/jn/134.2.465

[36] Gibson, G.R., Probert, H.M., Van Loo, J., Rastall, R.A. and Roberfroid, M.B. (2004) Dietary Modulation of the Human Colonic Microbiota: Updating the Concept of Prebiotics. Nutrition Research Reviews, 17, 259-275. https://doi.org/10.1079/NRR200479

[37] Ngoc, T.T.B., Hong, T.T.T., Len, N.T. and Lindberg, J.E. (2012) Effect of Fibre Level and Fibre Source on Gut Morphologyand Micro-environment in Local (Mong Cai) and Exotic (LandracexYorkshire) Pigs. Asian-Australasian Journal of Animal Sciences, 25, 1726-1733. https://doi.org/10.5713/ajas.2012.12305

[38] Hentges, D.J. (1992) Gut Flora and Disease Resistance. In: Fuller, R., Ed., Probiotics. The Scientific Basis, Chapman and Hall, London, 87-110. https://doi.org/10.1007/978-94-011-2364-8 5

[39] Wang, X. and Gibson, G.R. (1993) Effects of the in Vitro Fermentation of Oligofructose and Inulin by Bacteria Growing in the Human Large Intestine. Journal of Applied Bacteriology, 75, 373-380. https://doi.org/10.1111/j.1365-2672.1993.tb02790.x

[40] May, T., Mackie, R.I., Fahey, G.C., Cremin, J.C. and Garleb, K.A. (1994) Effect of Fibre Source on Short-Chain Fatty acid Production and on the Growth and Toxin Production by Clostridium difficile. Scandinavian Journal of Gastroenterology, 29, 916-922. https://doi.org/10.3109/00365529409094863

[41] Heinritz, S.N., Weiss, E., Eklund, M., Aumiller, T., Heyer, C.M.E., Messner, S., et al. (2016) Impact of a High-Fat or HighFiber Diet on Intestinal Microbiota and Metabolic Markers in a Pig Model. Nutrients, 8, 317. https://doi.org/10.3390/nu8050317

[42] Varel, V.H., Richardson, A.J. and Stewart, C.S. (1989) Degradation of Barley Straw, Ryegrass, and Alfalfa Cell Walls by Clostridium longisporum and Ruminococcus albus. Applied and Environmental Microbiology, 55, 3080-3084.

https://doi.org/10.1128/aem.55.12.3080-3084.1989

[43] McDonald, D.E., Pethick, D.W., Pluske, J.R. and Hampson, D.J. (1999) Adverse Effects of Soluble Non-Starch Polysaccharide (Guar Gum) on Piglet Growth and Experimental Colibacillosis Immediately after Weaning. Research in Veterinary Science, 67, 245-250. https://doi.org/10.1053/rvsc.1999.0315

[44] Bertschinger, H.U., Eggenberger, E., Jucker, H. and Pfirter, H.P. (1979) Evaluation of Low Nutrient, High-Fiber Diets for the Prevention of Porcine Escherichia coli Enterotoxaemia. Veterinary Microbiology, 3, 281-290.

https://doi.org/10.1016/0378-1135(79)90004-X

[45] Wellock, I.J., Fortomaris, P.D., Houdijk, J.G.M., Wiseman, J. and Kyriazakis, I. (2008) The Consequences of Non-Starch Polysaccharide Solubility and Inclusion Level on the Health and Performance of Weaned Pigs Challenged with Enterotoxigenic Escherichia coli. British Journal of Nutrition, 99, 520-530. https://doi.org/10.1017/S0007114507819167

[46] Liu, H.Y., Ivarsson, E., Dicksved, J., Lundh, T. and Lindberg, J.E. (2012) Inclusion of Chicory (Cichorium intybus L.) in Pigs' Diets Affects the Intestinal Microenvironment and the Gut Microbiota. Applied and Environmental Microbiology, 78, 4102-4109. https://doi.org/10.1128/AEM.07702-11 
[47] Ivarsson, E., Liu, H.Y., Dicksved, J., Roos, S. and Lindberg, J.E. (2012) Impact of Chicory Inclusion in a Cereal-Based Diet on Digestibility, Organ Size and Faecal Microbiota in Growing Pigs. Animal, 6, 1077-1085. https://doi.org/10.1017/S1751731111002709

[48] Ivarsson, E., Frankow-Lindberg, B.E., Andersson, K. and Lindberg, J.E. (2011) Growth Performance, Digestibility and Faecal Coliform Bacteria in Weaned Piglets Fed a Cereal-Based Diet Including Either Chicory (Cichorium intybus L.) or Ribwort (Plantago lanceolata L) Forage. Animal, 5, 558-564. https://doi.org/10.1017/S1751731110002193

[49] Macfarlane, G.T. and Macfarlane, S. (2012) Bacteria, Colonic Fermentation, and Gastrointestinal Health. Journal of AOAC INTERNATIONAL, 95, 50-60. https://doi.org/10.5740/jaoacint.SGE Macfarlane

[50] Cummings, J.H., Pomare, E.W., Branch, W.J., Naylor, C.P. and Macfarlane, G.T. (1987) Short Chain Fatty Acids in Human Large Intestine, Portal, Hepatic and Venous Blood. Gut, 28, 1221-1227. https://doi.org/10.1136/gut.28.10.1221

[51] Cummings, J.H. and Macfarlane, G.T. (1991) The Control and Consequences of Bacterial Fermentation in the Human Colon. Journal of Applied Bacteriology, 70, 443-459. https://doi.org/10.1111/j.1365-2672.1991.tb02739.x

[52] Wall, R., Ross, R.P., Shanahan, F., O’Mahony, L., O’Mahony, C., Coakley, M., Hart, O., Lawlor, P., Quigley, E.M., Kiely, B., et al. (2009) Metabolic Activity of the Enteric Microbiota Influences the Fatty Acid Composition of Murine and Porcine Liver and Adipose Tissues. The American Journal of Clinical Nutrition, 89, 1393-1401. https://doi.org/10.3945/ajen.2008.27023

[53] Russell, W.R., Gratz, S.W., Duncan, S.H., Holtrop, G., Ince, J., Scobbie, L., Duncan, G., Johnstone, A.M., Lobley, G.E., Wallace, R.J., et al. (2011) High-Protein, Reduced-Carbohydrate Weight-Loss Diets Promote Metabolite Profiles Likely to $\mathrm{Be}$ Detrimental to Colonic Health. The American Journal of Clinical Nutrition, 93, 1062-1072. https://doi.org/10.3945/ajcn.110.002188

[54] Smith, E.A. and Macfarlane, G.T. (1997) Dissimilatory Amino Acid Metabolism in Human Colonic Bacteria. Anaerobe, 3, 327-337. https://doi.org/10.1006/anae.1997.0121

[55] Newgard, C.B., An, J., Bain, J.R., Muehlbauer, M.J., Stevens, R.D., Lien, L.F., Haqq, A.M., Shah, S.H., Arlotto, M., Slentz, C.A., et al. (2009) A Branched-Chain Amino Acid-Related Metabolic Signature That Differentiates Obese and Lean Humans and Contributes to Insulin Resistance. Cell Metabolism, 9, 311-326.

https://doi.org/10.1016/j.cmet.2009.02.002

[56] Sanchez, J.I., Marzorati, M., Grootaert, C., Baran, M., Van Craeyveld, V., Courtin, C.M., Broekaert, W.F., Delcour, J.A., Verstraete, W. and Van de Wiele, T. (2009) Arabinoxylan-Oligosaccharides (AXOS) Affect the Protein/Carbohydrate Fermentation Balance and Microbial Population Dynamics of the Simulator of Human Intestinal Microbial Ecosystem. Microbial Biotechnology, 2, 101-113.

https://doi.org/10.1111/j.1751-7915.2008.00064.x

[57] Ragsdale, S.W. and Pierce, E. (2008) Acetogenesis and the Wood-Ljungdahl Pathway of $\mathrm{CO}_{2}$ Fixation. Biochimica et Biophysica Acta, 1784, 1873-1898. https://doi.org/10.1016/j.bbapap.2008.08.012

[58] Hetzel, M., Brock, M., Selmer, T., Pierik, A.J., Golding, B.T. and Buckel, W. (2003) Acryloyl-CoA Reductase from Clostridium propionicum. An Enzyme Complex of Propionyl-CoA Dehydrogenase and Electron-Transferring Flavoprotein. European Journal of Biochemistry, 270, 902-910. 
https://doi.org/10.1046/j.1432-1033.2003.03450.x

[59] Scott, K.P., Martin, J.C., Campbell, G., Mayer, C.-D. and Flint, H.J. (2006) Whole-Genome Transcription Profiling Reveals Genes Up-Regulated by Growth on Fucose in the Human Gut Bacterium "Roseburia inulinivorans". Journal of Bacteriology, 188, 4340-4349. https://doi.org/10.1128/JB.00137-06

[60] Louis, P., Duncan, S.H., McCrae, S.I., Millar, J., Jackson, M.S. and Flint, H.J. (2004) Restricted Distribution of the Butyrate Kinase Pathway among Butyrate-Producing Bacteria from the Human Colon. Journal of Bacteriology, 186, 2099-2106. https://doi.org/10.1128/JB.186.7.2099-2106.2004

[61] Duncan, S.H., Barcenilla, A., Stewart, C.S., Pryde, S.E. and Flint, H.J. (2002) Acetate Utilization and Butyryl Coenzyme A (CoA):Acetate-CoA Transferase in Butyrate-Producing Bacteria from the Human Large Intestine. Applied and Environmental Microbiology, 68, 5186-5190.

https://doi.org/10.1128/AEM.68.10.5186-5190.2002

[62] Le, M.H.A., Galle, S., Yang, Y., Landero, J.L., Beltranena, E., Gänzle, M.G., et al. (2016) Effects of Feeding Fermented Wheat with Lactobacillus reuteri on Gut Morphology, Intestinal Fermentation, Nutrient Digestibility, and Growth Performance in Weaned Pigs. Journal of Animal Science, 94, 4677-4687.

https://doi.org/10.2527/jas.2016-0693

[63] Hooper, L.V., Midtvedt, T. and Gordon, J.I. (2002) How Host Microbial Interactions Shape the Nutrient Environment of the Mammalian Intestine. Annual Review of Nutrition, 22, 283-307. https://doi.org/10.1146/annurev.nutr.22.011602.092259

[64] Agyekum, A.K., Regassa, A., Kiarie, E. and Nyachoti, C.M. (2016) Nutrient Digestibility, Digesta Volatile Fatty Acids, and Intestinal Bacterial Profile in Growing Pigs Fed a Distillers Dried Grains with Solubles Containing Diet Supplemented with a Multienzyme Cocktail. Animal Feed Science and Technology, 212, 70-80. https://doi.org/10.1016/j.anifeedsci.2015.12.006

[65] Brunsgaard, G. (1998) Effects of Cereal Type and Feed Particle Size on Morphological Characteristics, Epithelial Cell Proliferation, and Lectin Binding Patterns in the Large Intestine of Pigs. Journal of Animal Science, 76, 2787-2798. https://doi.org/10.2527/1998.76112787x

[66] Stanogias, G. and Pearce, G.R. (1985) The Digestion of Fibre by Pigs. 3. Effects of the Amount and Type of Fibre on Physical Characteristics of Segments of the Gastrointestinal Tract. British Journal of Nutrition, 53, 537-548. https://doi.org/10.1079/BJN19850063

[67] Jaworski, N.W., Lærke, H.N., Bach Knudsen, K.E. and Stein, H.H. (2015) Carbohydrate Composition and In Vitro Digestibility of Dry Matter and Nonstarch Polysaccharides in Corn, Sorghum, and Wheat and Coproducts from These Grains. Journal of Animal Science, 93, 1103-1113. https://doi.org/10.2527/jas.2014-8147

[68] Anugwa, F.O., Varel, V.H., Dickson, J.S., Pond, W.G. and Krook, L.P. (1989) Effects of Dietary Fiber and Protein Concentration on Growth, Feed Efficiency, Visceral Organ Weights and Large Intestine Microbial Populations of Swine. The Journal of Nutrition, 119, 879-886. https://doi.org/10.1093/jn/119.6.879 